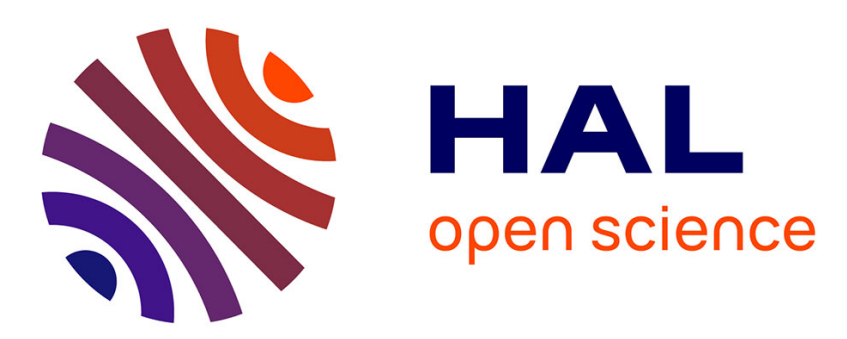

\title{
Housing market regulation and the social demand for job protection
}

Bruno Decreuse, Tanguy van Ypersele

\section{To cite this version:}

Bruno Decreuse, Tanguy van Ypersele. Housing market regulation and the social demand for job protection. 2010. halshs-00481456

\section{HAL Id: halshs-00481456 \\ https://shs.hal.science/halshs-00481456}

Preprint submitted on 6 May 2010

HAL is a multi-disciplinary open access archive for the deposit and dissemination of scientific research documents, whether they are published or not. The documents may come from teaching and research institutions in France or abroad, or from public or private research centers.
L'archive ouverte pluridisciplinaire HAL, est destinée au dépôt et à la diffusion de documents scientifiques de niveau recherche, publiés ou non, émanant des établissements d'enseignement et de recherche français ou étrangers, des laboratoires publics ou privés. 


\section{GREQAM}

Groupement de Recherche en Economie Quantitative d'Aix-Marseille - UMR-CNRS 6579

Ecole des Hautes Etudes en Sciences Sociales Universités d'Aix-Marseille II et III
HOUSING MARKET REGULATION AND THE SOCIAL DEMAND FOR JOB PROTECTION

\author{
Bruno DECREUSE \\ Tanguy VAN YPERSELE
}

April 2010
Document de Travail $n^{\circ}$ 2010-11 


\title{
Housing market regulation and the social demand for job protection* $^{*}$
}

\author{
Bruno Decreuse $^{\dagger}$ \\ GREQAM, University of Aix-Marseilles \\ Tanguy van Ypersele $\ddagger$ \\ GREQAM, University of Aix-Marseilles, and CEPR \\ This version: April 2010
}

\begin{abstract}
Controlling for country fixed effects, there is a positive and statistically significant relationship between the degree of housing market regulation (HMR) and the strictness of employment protection legislation (EPL) in OECD countries. We provide a model in which HMR increases foreclosure costs in case of mortgage default, while EPL raises the administrative cost of dismissal. Owing to banks' lending behavior, individuals' demand for job protection increases with the cost of foreclosure. We use the model to discuss social housing and family insurance, the case for mortgage unemployment insurance, regulations on the use of fixed-term contracts, the impact of min down-payment policies, feed-back effects from HMR to EPL, and the failure of a 2006 French reform of the labor contracts.
\end{abstract}

Keywords: Foreclosure costs; Job protection; Fixed-term contracts; CPE

JEL classification: G2; R2; K31

\footnotetext{
*This paper benefited from the comments of participants attending at seminars at the University of Aix-Marseilles and University of New South Wales, and participants at the 2008 OLG workshop in Aix-en-Provence, the 2008 Australasian meeting of the Econometric Society in Wellington, the 2009 Journées Louis-André Gérard-Varet in Marseilles, and the 2009 ASSET meeting in Istanbul. We also thank Pierre Cahuc, Jean-Olivier Hairault, Carsten Ochsen, and Andrew Postlewaite for useful discussions. This research was partly funded by the Conseil Régional Provence Alpes Côte d'Azur. The usual caveat applies.

†GREQAM - 2, rue de la charité 13236 Marseilles cedex 2, France. E-mail: decreuse@univmed.fr

${ }^{\ddagger}$ GREQAM - 2, rue de la charité 13236 Marseilles cedex 2, France. E-mail: tanguy.vanypersele@univmed.fr
} 


\section{Introduction}

In April 2006, the French Government created a new type of labor contract targeting youth. This contract was named the Contrat Première Embauche (first employment contract), or CPE for short. The main purpose of the $\mathrm{CPE}$ was to reduce the cost of administrative procedures related to dismissals for jobs occupied by young workers. Student unions militated against this proposal, and huge numbers of young people demonstrated out in the streets and occupied faculties. Some of their leaders became media icons. To many observers, most of them foreigners, these demonstrations were a pure illustration of the ideological bias of the French society as a whole: students demanding and obtaining the shelving of legislation that was supposed to improve their economic perspectives. ${ }^{1}$ We consider another explanation to the behavior of the French students. This explanation is based on housing market imperfections and their impacts on the willingness of people to adopt a legislation that reduces job security.

The housing market is very far from the typical neoclassical market. The permanent or temporary exchange of durable goods involves long-term contracts. In the rental case, the owner temporarily transfers his property right to the tenant against rent payment. In the mortgage case, the bank finances (part of) the purchase of the house in exchange for mortgage reimbursement. The landlord and the bank have to be able to recover the property in case of rent or mortgage default. This is the enforcement problem identified by Djankov et al (2003). Legal systems heavily regulate contract enforcements in the housing market. Such regulations generate costs that are lost for the owner and tenant or for the bank and borrower. In turn, the magnitude of such costs affects lenders and dwellers who become more circumspect as to the borrower's or tenant's income security. In this context, getting a secured job not only insures against labor market-specific risk but also facilitates access to the housing market. A key implication is that the need for job protection increases with procedural formalism, that is with the degree of housing market regulation (HMR).

We proceed in three steps. In Section 2, we present a set of facts that motivate our thesis. At the micro level, job security improves youth emancipation and household ownership. This holds true for a variety of controls, including age and wage income. At the macro level, we use the procedural formalism index of Djankov et al (2003) to measure the degree of HMR, and we use the OECD EPL index to quantify the strictness of EPL. These indices are positively correlated in the cross-section of OECD countries. We use dynamic panel data covering 15 OECD countries over the period 1950-2000. Data are averaged over 5 years, and the panel is balanced. We show that the correlation is robust to country fixed effects, time effects, and to the consideration of inertia in the strictness of EPL. We also provide evidence of causal effects: EPL responds to lagged HMR, while neither current nor lagged EPL affects HMR.

We then develop, in Section 3, a model to explain why HMR should influence EPL. The idea is to capture some form of social cohesion behind EPL. We want to understand why a young person can be in favor of EPL despite the fact that job protection is detrimental to job creation. The framework is a static matching model with endogenous job creation and job destruction. EPL determines firing costs, thereby increasing job stability but decreasing the matching probability. We consider ex-ante risk neutral agents. The demand for EPL does not build on exogenous risk aversion, but stems from endogenous risk

\footnotetext{
${ }^{1}$ Economic gains were not so obvious. Cahuc and Carcillo (2006) focus on the case of the Contrat Nouvelle Embauche, an employment contract very close to the CPE. Compared to short-term contracts, the CNE reduces the probability of obtaining a regular job. Depending on the discount rate, unemployed welfare may decrease with the CNE even though the unemployment rate goes down.
} 
aversion originated by HMR. In our setting, individuals only derive utility from housing. To buy a house, a person takes a mortgage pledging his future income. HMR is modeled as a foreclosure cost for the bank. In case of default, the bank expects to recover only part of its investment. Banks only lend to employed agents and expect some losses when the borrower loses his job. Strengthening EPL lowers the default probability and reduces the expected loss for the bank. Competitive banks offer lower mortgage prices as a result. The preferred EPL parameter results from the following trade-off: on the negative side, an increase in EPL may deteriorate the employment probability, but on the positive side it decreases the borrowing cost. We show that the demand for EPL is an increasing function of the degree of HMR.

In Section 4, we extend our model in several directions and discuss various implications. We first account for social housing or other alternative housing arrangements like coresidence with parents. Such a type of housing supply raises the returns to EPL as it makes unemployment less painful. The second extension examines housing unemployment insurance. Insurance coverage is very limited: empirical studies show that high-risk borrowers are typically excluded from insurance coverage. The third extension is motivated by the dramatic increase in the use of short-term contracts in European countries. That increase partly results from the strictness of EPL on long-term contracts, but also from more flexible regulations on the use of temporary jobs. Boeri and Garibaldi (2009) argue that the increase in the supply of short-term jobs has reduced unemployment, but in a way that dissatisfies European citizens. Our model can explain this paradox: unemployed individuals may favor taxes on the use of short-term contracts despite such taxes lowering the odds of employment. Solving the unemployment problem at the expense of job stability may turn against the policy maker in that case. The fourth extension extends our analysis of HMR to regulations that limit access to mortgage credit. Such regulations weaken the political support for job protection as they reduce the return on job security induced by a better loan. The fifth extension investigates the scope for reverse causality, from EPL to HMR. We complete the basic model: individuals face two different default risks, and they are covered by a housing insurance obtained at the expense of the bank. Dispute resolution implies that the loss for the bank is larger than the gain for the defaulting person. We show that EPL has an ambiguous impact on the social demand for HMR. Finally, we revisit the 2006 French CPE events and argue that the timing of the reform was typically misconceived. The Government should have first reformed the housing market and then introduced the labor market reform. The opposite occurred: a housing market reform took place six months after the failure of the labor market reform.

This paper adds to the growing literature on the positive analysis of employment protection. This literature aims at understanding the degree of employment protection specific to each country. As explained by Botero et al (2004), labor market regulation has three explanations: rent-seeking, the legal origins of the judicial system, and market failures.

According to the rent-seeking argument, EPL maximizes the rent situation of insider workers who benefit from a long-term contract. ${ }^{2}$ In this approach, individuals are reduced to their selfish interests. They have no family, and especially no children or wife who may suffer from labor market rigidity. The political insider model emphasized by Saint-Paul (2001) predicts strong intergenerational conflicts over EPL. However, such conflicts are not obvious when one examines the CPE events. Our paper takes a complementary road as it focuses on young nonemployed individuals. Doing so, we argue that

\footnotetext{
${ }^{2}$ However, workers in dying industries/jobs may have preferences very similar to those of the unemployed. See Saint-Paul (2002).
} 
intergenerational conflicts are not so strong over EPL: young workers are more willing to obtain a rent or a mortgage, which tends to increase their demand for job protection above the point that maximizes their employment probability.

The legal origins argument considers that the regulation of labor depends on the fundamental characteristics of the judicial system (Botero et al, 2004). Common-law judicial systems lower the need for regulation as they are characterized by the importance of decision-making by juries, independent judges, and the emphasis on judicial discretion as opposed to code. In a more general interpretation, this argument hinges on the idea that predetermined traits of a society mostly explain the set of institutions that rule the country: the legal origins, but also cultural factors like machismo, the dominant religion, or civic attitudes (see Algan and Cahuc, 2006, 2009). Our paper takes a complementary approach whereby job protection emerges as a rational response to a regulated housing market. Of course, cultural factors simultaneously affect regulation on the labor and housing markets. However, the dynamic data we use in Section 2 allow us to control for country fixed effects and identify a statistically significant relationship between HMR and EPL.

The market failure argument analyses EPL as a way to improve welfare in the context of market imperfections. Blanchard and Tirole (2008) for instance examine the optimal design of unemployment coverage in light of various market failures. This part of the literature highlights the role played by institutions that are not directly related to job dismissals. Such institutions can be substitutable or complementary to EPL. For instance, unemployment insurance and job protection are substitutable because they both cover employees against unemployment risk (see Boeri et al, 2003), while product market regulations and job protection are complementary because job protection secures the share of rents accruing to employees (see Kugler and Pica, 2006). Our paper relies on this literature by pointing out the need to focus on policy complementarity at the time of reform. Our innovation consists in highlighting the role of the housing market.

The idea whereby housing market imperfections originate risk aversion thereby creating a social demand for job protection relies on the literature on consumption commitments. Consumption commitments allow the price of consumption goods to be reduced. However, commitments must be honored, thus creating risk aversion. Chetty (2008) argues that unemployment benefits raise durations through a "liquidity" effect for households who cannot smooth consumption perfectly - typically those with low assets or mortgage repayments. Turning to welfare implications, he concludes that the optimal replacement rate is above $50 \%$ of the former wage, a ratio that is higher than previous studies found. In the same vein, Postlewaite et al (2008) argue that consumption commitments induce workers to sign labor contracts that possibly involve an unemployment stage. As in those papers, risk aversion is endogenous in our paper. Beyond our focus on national legislations and international comparisons, our paper innovates by letting the degree of risk aversion vary with housing market regulation.

The remainder of the paper is organized as follows. Section 2 presents micro and macro stylized facts. Section 3 introduces our model and discusses the positive impact of housing market regulations on the willingness to secure jobs. Section 4 discusses several aspects of the model and extends it in various directions. Section 5 concludes. 


\section{Empirical evidence}

This section presents empirical evidence motivating our analysis. We first discuss the microeconomic evidence that relates job security to housing access. We then examine within and between country correlations between EPL strictness and the degree of HMR.

\subsection{Microeconomic evidence}

In this subsection, we argue that job security facilitates access to housing.

The first piece of evidence comes from the study of coresidence rates between parents and offspring for various age groups. Coresidence rates after 20 or after 25 vary considerably between countries. Such rates are typically very high in Mediterranean European countries, with an Italian leader and a French exception. By contrast, they are much lower in Nordic countries and in the UK. Part of this heterogeneity reflects cultural differences. However, economic performance via its impact on youth unemployment and youth job insecurity may have an impact on youth emancipation. Becker et al (2009) use Italian individual data on perceived job security. Controlling for income level, they show that unemployment and youth job insecurity are negatively correlated with the probability of emancipation.

The second piece of evidence comes from studies on home ownership probability. Serrano-Diaz (2005a) uses European data from the European Community Household Panel and tries to explain household probability of home ownership. He builds an index of income volatility and shows that the probability of home ownership decreases with income volatility. Probit regressions control for country fixed effects and for individual variables like age and education, but also wage and financial resources. The latter controls are important as income volatility may be correlated with income level.

The third piece of evidence relates to the determinants of the risk of mortgage default. Deng et al (1996) on US data shows that unemployment episodes increase the default probability. Eichholtz (1995) focuses on the Netherlands and shows that regional employment stability is correlated with regional rates of default. Serrano-Diaz (2005b) uses ECHP data and considers the delinquency risk rather than the default probability. He shows that household delinquency probability increases with income volatility as well as after an unemployment episode. Estimates control for sample selection bias, because the distribution of unobserved characteristics among households who borrowed generally differs from the distribution of characteristics among the whole population. The number of delinquency episodes is low: the mean delinquency rate is approximately $2.5 \%$ in the whole sample. It suggests that banks severely screen the potential borrowers, and successfully reject high-risk borrowers. In all likelihood, owners do the same prior to renting.

\subsection{Macroeconomic evidence}

In this subsection, we focus on the correlation between the degree of HMR and the strictness of EPL.

EPL covers a variety of regulations affecting workers' dismissals like procedural requirements, notice and severance pay requirements, penalties for unfair dismissals, regulations to the use of temporary work and short-term contracts, specific regulations applying to collective dismissals. The OECD provides three synthetic indices depicting the strictness of regulations in three complementary areas: the protection of regular jobs, the use of temporary workers and short-term contracts, and the specific rules applying to 
collective dismissals. These indices are aggregated within two general indices: EPL1 equals one half the index on regular jobs plus one half the index on the use of short-term contracts. EPL2 equals 5/6 EPL1 plus $1 / 6$ the index on collective redundancies. EPL1 and EPL2 are only available for OECD countries. EPL1 has three observations per country (end 1980s, end 1990s, and 2003). EPL2 has two observations (end 1990s and 2003). Using the OECD methodology, Allard (2005) provides and complements EPL2 for each year between 1950 and 2006. We use her index hereafter.

HMR covers the rental and the mortgage markets. We are interested in the subset of regulations that weaken property rights. Chiuri and Japelli (2003) focus on two measures of the cost of foreclosure in case of buyer's default. Those measures are the mean duration of housing mortgage foreclosure proceedings (in months) and the average legal expenses in percentage of the price of the mortgaged house. These measures have two main shortcomings. First, they do not directly measure regulations, but some of their potential implications. Foreclosure expenses and duration are endogenous. Second, they are only available for a restricted number of countries, and there is a single observation per country.

Therefore, we consider two indices of procedural formalism that have been built by Djankov et al (2003). They focus on two disputes: the eviction of a tenant who does not pay the rent, and the collection of a bounced check. In both cases, the index is built from several sub-indices that describe the exact procedure used by litigants and courts: the required degree of professionalism of lawyers and judges, the preeminence of written versus oral presentation at each stage of the procedure, the need for legal justification in the complaint and in the judgment, the rules of evidence, the appeal procedure, engagement formalities that must be observed before a party is legally bound by the court proceedings, and the number of independent procedural actions. Djankov et al show that higher procedural formalism predicts longer duration of dispute resolution, lower enforceability of contracts, higher corruption, as well as lower honesty, consistency, and fairness of the system. The tenant eviction index directly applies to the rental market. The bounced check index is not directly related to the housing market. However, it can be used as a global measure of the legal difficulties to recover a debt, whether on the product or mortgage markets. In the 2003 paper, both indices were only available for a year. Balas et al (2009) extend the coverage and the indices are available on a yearly basis between 1950 and 2000 for 40 developed and developing countries. We follow them and consider the indices for the 15 OECD countries of their sample. ${ }^{3}$

The tenant eviction index and the bounced check index are almost perfectly correlated. The correlation coefficient is .93. Hereafter we only focus on the tenant eviction index, having in mind that the index captures more than the regulation on the rental market.

\footnotetext{
${ }^{3}$ The 15 countries are Australia, Austria, Belgium, Canada, France, Germany, Italy, Japan, Netherlands, New Zealand, Portugal, Spain, Sweden, United Kingdom, United States.
} 


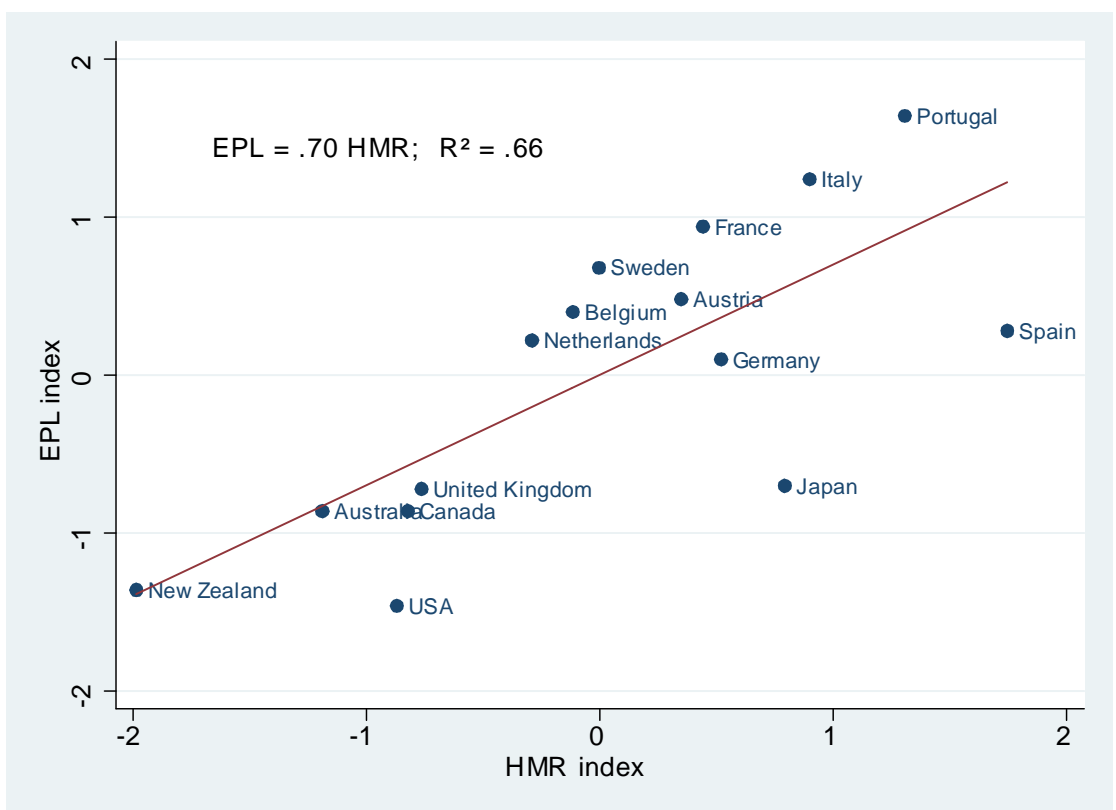

Figure 1: The relationship between HMR and EPL, 1995-2000. The variables have been averaged over five years and centered around their period means. The straight line is the least-square regression.

\begin{tabular}{c|l|cccc}
\hline \hline variables & & mean & st.dev & $\min$ & $\max$ \\
\hline \multirow{3}{*}{ EPL } & overall & 0 & .96 & -1.98 & 1.84 \\
& between & & .86 & -1.27 & 1.29 \\
& within & & .46 & -1.32 & .98 \\
\hline \multirow{3}{*}{ HMR } & overall & 0 & 1.01 & -2.16 & 2.08 \\
& between & & 1.00 & -1.64 & 1.76 \\
& within & & .31 & -1.32 & 1.09 \\
\hline \hline
\end{tabular}

Table 1: Descriptive statistics

As institutional variables do not change frequently, we average data over five-year periods. This leaves us with 10 observations for 15 countries. We substrate the period mean to each observation to purge the data from trends and aggregate shocks that affect all countries simultaneously. Table 1 shows that there is substantial variation in the dataset. The standard deviation is one fourth of the maximum variation for each index. Table 1 also shows that there is more volatility to exploit in the cross-section dimension than in the time dimension. However, the volatility is sufficiently large within countries to apply dynamic panel data analysis.

Figure 1 displays the correlation between the EPL index and the HMR index over the period 19952000. The correlation is positive. However, the correlation between HMR and EPL in the cross-section of countries does not prove that HMR and EPL are effectively related with each other. The correlation may be spurious, reflecting country-specific factors that simultaneously affect HMR and EPL.

To account for country-specific factors, we exploit the dynamic panel structure of the data and run 
fixed effects regressions. Table 2 shows that the EPL and HMR indices are positively correlated. Table 2 also suggests that this correlation reflects causality from HMR to EPL.

\begin{tabular}{c|ccccc}
\hline \hline & (a) & (b) & (c) & (d) & (e) \\
\hline $\mathrm{HMR}_{t}$ & $.65^{* * *}$ & $.37^{* * *}$ & -.08 & & \\
& $(.05)$ & $(.10)$ & $(.10)$ & & \\
$\mathrm{HMR}_{t-1}$ & & & $.25^{* *}$ & $.18^{* *}$ & $.30^{* *}$ \\
& & & $(.11)$ & $(.08)$ & $(.15)$ \\
$\mathrm{EPL}_{t-1}$ & & & $.76^{* * *}$ & $.76^{* * *}$ & $.89^{* * *}$ \\
& & & $(.07)$ & $(.07)$ & $(.09)$ \\
Fixed Effects & no & yes & yes & yes & yes \\
$\mathrm{R}^{2}$ & .48 & .06 & .64 & .64 & \\
\hline No obs & 150 & 135 & 135 & 135 & 135 \\
Sargan & & & & & .26 \\
Hansen & & & & & .19 \\
AR $(2)$ & & & & & .58 \\
\hline \hline
\end{tabular}

Table 2: The impact of HMR on EPL with panel data. The dependent variable is the EPL index. Robust standard errors in brackets. Column a reports the OLS estimates when we pool the data. Columns b to d report fixed effects estimates and the within $\mathrm{R}^{2}$. Column e reports two-step system-GMM estimates. Estimations were made using the Stata command xtabond2. The number of GMM-style instruments was reduced using the option collapse. Lines Sargan and Hansen provide the P-values for the Sargan and Hansen tests of overidentifying restrictions. The null is that instruments are not correlated with the residuals. Line $\operatorname{AR}(2)$ is the P-value for the Arellano-Bond second-order auto-correlation test. The null is that errors in the difference regression do not exhibit second-order correlation. Significance levels: * $10 \%, * * 5 \%, * * * 1 \%$

We proceed in four steps.

Column a reports pooled estimates. It confirms the visual guess displayed by Figure 1 . The $\mathrm{R}^{2}$ is remarkably high, given that the HMR index is the only explicative variable. However, as explained below, the correlation may be driven by country-specific factors. It may also be due to strong autoregressive components in the dynamic processes of the EPL and HMR indices.

Column b reports fixed effects estimates. Fixed effects allow country-specific factors that do not change over time to be controlled. This includes the legal origins of the judicial system, ideological biases, but also cultural factors that change very slightly over time. Column b shows that the correlation between EPL and HMR is robust to such fixed effects, though the magnitude of the parameter associated with HMR is cut by half.

Columns $\mathrm{c}$ and $\mathrm{d}$ account for the dynamics of the dependent and explicative variables. As expected from the measure of an institution, the strictness of EPL is very sluggish: the estimated parameter associated with the lagged dependent variable is .76. Consideration of the lagged dependent variable lowers the magnitude of the relationship between HMR and EPL. The parameter amounts to one-third of the value displayed in column a. However, it is still significant at $5 \%$. Columns $\mathrm{c}$ and d display another 
piece of information. The current level of EPL is affected by the past level of HMR and not by its current level. This result is in favor of a causal relationship from HMR to EPL.

To investigate the causal relationship from HMR to EPL, we run an auxiliary regression. We try to explain HMR as a function of current and lagged EPL. The following relationship is obtained:

$$
\mathrm{HMR}_{i t}=\widehat{a}_{i}-\underset{(.04)}{.04} \mathrm{EPL}_{i t}+\underset{(.04)}{.04 \mathrm{EPL}_{i t-1}}+\underset{(.10)}{.86} \mathrm{HMR}_{i t-1}+\widehat{\varepsilon}_{i t}
$$

where robust squared errors are in brackets. The parameters associated with EPL variables have a very small magnitude, and they are nonsignificant at any reasonable level. These estimates confirm the view whereby HMR causes EPL, while HMR does not seem to cause EPL.

Column e reports system-GMM estimates (Blundell and Bond, 1998). The fixed effects estimator is biased in finite sample because the lagged dependent variable is correlated with the error term. Formally, the model is written as follows:

$$
\begin{aligned}
\Delta \mathrm{EPL}_{i t} & =a^{1} \Delta \mathrm{EPL}_{i t-1}+a^{2} \Delta \mathrm{HMR}_{i t-1}+\Delta \varepsilon_{i t} \\
\mathrm{EPL}_{i t} & =a^{1} \mathrm{EPL}_{i t-1}+a^{2} \mathrm{HMR}_{i t-1}+\varepsilon_{i t}
\end{aligned}
$$

The model has two components: the difference and level submodels. In both components, the lagged dependent variable is correlated with the error terms and must be instrumented. In addition, $\mathrm{HMR}_{i t-1}$ may be correlated with $\varepsilon_{i t-1}$, which also requires an instrumenting strategy. In the absence of good instruments, the set of instruments only contains lagged regressors. In the difference submodel, the differenced lagged EPL index is instrumented by past levels of the index (from $\mathrm{EPL}_{i t-2}$ ), while the lagged EPL index is instrumented by past differences of the index in the level submodel (from $\Delta \mathrm{EPL}_{i t-1}$ ). This generates a large number of instruments in GMM-style. The set of instruments is finally reduced by collapsing the matrix of GMM-style instruments to avoid the overinstrumenting bias. ${ }^{4}$ Similarly, the regressors $\Delta \mathrm{HMR}_{i t-1}$ and $\mathrm{HMR}_{i t-1}$ are instrumented by their own lags. The model is estimated by two-step GMM, while reported squared errors feature Windmeijer correction to correct for individual heteroskedasticity, arbitrary patterns of autocorrelation within individuals, and downward bias in squared errors in finite samples.

GMM estimates confirm fixed effects estimates, which suggests that the endogeneity bias is not very large in the fixed effects regressions. Overall, HMR affects EPL with a five-year delay. This effect is robust to the consideration of country-specific effects, time effects, and to the introduction of the lagged dependent variable among the regressors. Quantitatively, increasing the HMR index by one-standard deviation leads to a one-fourth standard deviation increase in the EPL index.

In the next section, we present a model of the housing and labor markets that can explain why the degree of regulation on the housing market can affect the willingness of people to secure their jobs.

\section{The demand for EPL with HMR}

This section introduces a model of the labor and housing markets that features a social demand for EPL at given HMR. We consider a static economy peopled by identical individuals. We focus on the demand

\footnotetext{
${ }^{4}$ The number of instruments increases with the time index of each observation. The total number of instruments is quadratic in the number of periods as a result. Collapsing allows such a number to be reduced, while exploiting the same information displayed by the dataset (see Roodman, 2006).
} 
of those agents for job protection before entering market activities such as searching for a job, working, and enjoying housing consumption. We examine this demand under the veil of ignorance to disentangle our analysis from papers focusing on the insider-outsider dichotomy. All individuals start unemployed and we study their preferences over EPL prior to knowing whether they will be employed or not. This assumption has various advantages. First, we abstract from vested interests and rent protection that have been discussed so far. Second, EPL is efficient in a second-best environment characterized by various forms of market imperfections. Third, we avoid the general critique addressed to political economy models of labor market institutions: prime-aged people do not vote against the interests of their own children in our approach. By focusing on the welfare of a (young) nonemployed and nonhoused person, we capture the social cohesion relating job protection that we observe in many European countries.

The model has two blocks. In the labor market block, employment opportunities and job loss probability decrease with an index that captures the EPL effects. The housing market block features imperfections on the credit market. The only purpose of income is to buy housing units. Once an individual has obtained a job, he borrows money from the bank. The mortgage is repaid at the end of the period if the individual did not get fired. In case of job loss, we assume individuals default. The bank only recovers a share of the mortgaged housing, while the remaining share is lost. The proportion that is lost is exogenous, and measures the degree of housing market imperfections.

The model we present can be reinterpreted to analyze the rental market. In that case, substitute owner for bank and rent for mortgage.

Formally, the model is as follows: we assume a unit mass of homogenous risk neutral agents living one period and starting the period as unemployed.

Timing. In a first stage, EPL is set. In a second stage, households search for a job. They find it with probability $m$. Once the job is found, the wage $w$ is determined. We normalize unemployment benefits to zero. In a third stage, households buy/rent housing on the basis of their employment contract. The unit price of the rent/buy is $R$. It is endogenous. To simplify, housing consumption is the only purpose of income. In a fourth stage, the productivity of each job unfolds making some jobs potentially unprofitable. We model the EPL as a dismissal cost. Therefore, the probability that a job is not destroyed is given by $p$ and is increasing with the strictness of EPL. Only those who stay employed pay the mortgage, and benefit from housing consumption.

The model must be solved backward. We now present it in greater details.

Labor market. There is a continuum of firms. Each firm corresponds to a single job slot, which can be active or inactive. Turning active $\operatorname{costs} c>0$. Vacant jobs and unemployed workers meet according to a matching technology. Let $\theta$ be the ratio of vacant jobs to unemployed workers. The probability of receiving a job offer is $\mu(\theta)$, while the probability of recruiting a worker is $\mu(\theta) / \theta$, with $\mu(0)=0$, $\mu(\infty)=1, \mu^{\prime}>0, \mu^{\prime \prime}<0$, and $\mu^{\prime}(0)=1$. The strict concavity implies that $\mu(\theta) / \theta$ is strictly decreasing, while the Inada-type condition ensures that $\lim _{\theta \rightarrow 0} \mu(\theta) / \theta=1$ by l'Hôpital's rule. ${ }^{5}$

Once the worker is hired, the productivity of the job is revealed. The firm chooses whether to continue the employment relationship or not. The productivity of the job results from a random draw from the distribution $F$ over the support $(-\infty, \infty)$.

EPL strictness is captured as follows. The firing cost $t \geq 0$ is a pure loss to the firm. We do not consider redundancy premia paid to the worker as they are typically low with respect to the wage. The

\footnotetext{
${ }^{5}$ These assumptions are compatible with the urn-ball matching technology.
} 
rationale for such a neglect is a non-formalized moral hazard problem.

We assume an exogenously fixed wage $w$. Appendix A considers alternative wage settings. What matters is not the way the wage is set but rather that the wage cannot be changed ex-post, that is once the productivity of the job is known. At wage $w$ and EPL $t$, operating profit is $y-w$. The worker is dismissed if and only if $y-w<-t$. Therefore, expected profit is

$$
\pi(w, t)=\int_{w-t}^{\infty}(y-w) d F(y)-F(w-t) t
$$

with

$$
\begin{aligned}
& \frac{\partial \pi(w, t)}{\partial w}=-[1-F(w-t)] \\
& \frac{\partial \pi(w, t)}{\partial t}=-F(w-t)
\end{aligned}
$$

Under free entry,

$$
c=\frac{\mu\left(\theta^{*}\right)}{\theta^{*}} \pi(w, t)
$$

This equality holds if and only if $\pi(w, t) \geq c$. Tightness decreases with wage and firing cost. It follows that both the job-finding probability $m(t)=\mu\left(\theta^{*}\right)$ and the job destruction probability $1-p(t)=F(w-t)$ decrease with the firing cost. For simplicity, we assume that $\mathbb{E}(y)-w<c$ : no jobs are created when the firing cost becomes arbitrarily large.

For later use we define the following elasticities. The elasticity of the job-finding probability with respect to the firing cost is given by

$$
\frac{t m^{\prime}(t)}{m(t)}=-\frac{\gamma(\theta(t))}{1-\gamma(\theta(t))} \frac{t F(w-t)}{\pi(w, t)}
$$

where $\gamma(\theta) \equiv \theta \mu^{\prime}(\theta) / \mu(\theta) \in(0,1)$ is the elasticity of $\mu$ with respect to $\theta$. Similarly, the elasticity of the job loss probability with respect to $t$ is written

$$
\frac{t p^{\prime}(t)}{p(t)}=\frac{t F^{\prime}(w-t)}{1-F(w-t)}
$$

Housing market. The housing market imperfection is formalized as follows. If a worker is dismissed, he defaults on the mortgage. In case of default, the bank (or the insurance company if the bank is insured) only recoups a share $1-\alpha \in[0,1]$ of the value that has been contracted. The parameter $\alpha$ is the index of HMR. This cost is a pure loss for the economy. In this section, we analyze the demand for EPL for a given $\alpha .{ }^{6}$ Finally, there is perfect competition between suppliers on the housing market.

Consider the mortgage case. We normalize the bank's marginal cost of money to one. The marginal return depends on the price paid by the borrower, the default probability $1-p$, and the parameter $\alpha$. With perfect competition on the banking sector, we have

$$
1=p R+(1-p)(1-\alpha)
$$

It follows that the mortgage price is

$$
R=1+\alpha \frac{1-p}{p}
$$

\footnotetext{
${ }^{6}$ In subsection 4.5 , we discuss the potential endogeneity of HMR.
} 
The price is increasing in $\alpha$, from 1 when $\alpha=0$ to $1 / p$ when $\alpha=1$. It is also decreasing in $p$, as the price is an increasing function of the default probability. This effect is all the higher in so far as the distortion $\alpha$ is significant. The crucial point is that increasing job security lowers the mortgage price when the housing market is regulated.

In the rental case, the interpretation of equations (10) and (11) is as follows: the marginal cost of constructing a unit of housing is normalized to one, $R$ is the rent, and $1-\alpha$ is the proportion of the opportunity cost that can be refunded once the owner effectively separates from the tenant who does not pay the rent.

Individual preferences. Individuals are risk neutral. This assumption is made for two reasons. On the one hand, our point is not related to optimal insurance design against income risk. On the other hand, HMR originates a particular form of risk aversion that is easier to understand when agents are initially risk neutral. The expected utility of the representative agent is:

$$
U=m p \frac{w}{R}
$$

The product $m p$ is the employment probability, while $w / R$ is the real wage, that is the number of units of housing consumption. The unemployed have no housing consumption.

The demand for EPL results from

$$
t^{*} \in \arg \max _{t \geq 0}\left\{U(t)=m(t) p(t) \frac{w}{R(t)}\right\}
$$

The maximization problem $\left(\mathrm{P}_{1}\right)$ may admit a corner solution where $t^{*}=0$. This may be so when $U^{\prime}(0)<0$. If such a corner solution holds, individuals are reasonably happy with the working of the labor and credit markets and do not demand further protection on the labor market. We assume that $U^{\prime}(0)>0$ so that there is an interior solution to the maximization problem $\left(\mathrm{P}_{1}\right)$. Such a solution results from the following first-order condition:

$$
\frac{t^{*} p^{\prime}\left(t^{*}\right)}{p\left(t^{*}\right)}+\left|\frac{t^{*} R^{\prime}\left(t^{*}\right)}{R\left(t^{*}\right)}\right|=\left|\frac{t^{*} m^{\prime}\left(t^{*}\right)}{m\left(t^{*}\right)}\right|
$$

The right-hand side refers to the marginal cost of EPL, that is a lower job-finding probability. The left-hand side refers to the marginal benefit derived from EPL. It is composed of two terms. The first term is the return on job security: the stricter EPL, the lower the job-loss probability. The second term is the return on housing price: an increase in job security lowers housing cost. In the absence of this latter return, EPL would simply be chosen so as to maximize the employment probability.

We compute the elasticity of housing price with respect to EPL from (11):

$$
\frac{t R^{\prime}(t)}{R(t)}=-\frac{\alpha}{\alpha+(1-\alpha) p(t)} \frac{t p^{\prime}(t)}{p(t)}
$$

It is proportional to the elasticity of the probability of keeping one's job with respect to the EPL parameter. The (absolute value of the) factor of proportion increases with $\alpha$. Replacing (14) in (13), we get:

$$
\frac{t^{*} p^{\prime}\left(t^{*}\right)}{p\left(t^{*}\right)}\left[1+\frac{\alpha}{\alpha+(1-\alpha) p\left(t^{*}\right)}\right]=\left|\frac{t^{*} m^{\prime}\left(t^{*}\right)}{m\left(t^{*}\right)}\right|
$$

Using (8) and (9), and assuming that $U^{\prime}(0)>0$, optimal EPL $t^{*}$ is implicitly defined by

$$
\frac{t^{*} F^{\prime}\left(w-t^{*}\right)}{1-F\left(w-t^{*}\right)}\left[1+\frac{\alpha}{\alpha+(1-\alpha)\left[1-F\left(w-t^{*}\right)\right]}\right]=\frac{\gamma\left(\theta\left(t^{*}\right)\right)}{1-\gamma\left(\theta\left(t^{*}\right)\right)} \frac{t^{*} F\left(w-t^{*}\right)}{\pi\left(w-t^{*}\right)}
$$


Proposition 1 HMR And optimal Job PROteCtion. Let $t^{*}$ be unique with $t^{*}>0$ and consider a marginal increase in the degree of HMR $\alpha$. Then, (i) Optimal job protection $t^{*}$ goes up, that is $d t^{*} / d \alpha>0$, and (ii) the equilibrium employment rate $m\left(t^{*}\right) p\left(t^{*}\right)$ goes down, that is $d m\left(t^{*}\right) p\left(t^{*}\right) / d \alpha<0$

HMR raises the net return on job security. Job security not only affects welfare because it decreases the probability of dismissal, it also reduces the housing cost. This second effect is all the larger in so far as the housing market is regulated. The effect is nil when $\alpha=0$, while the total return on job security is counted twice when $\alpha=1$. Therefore, the social demand for EPL increases with HMR.

Proposition 1 provides a local result. It does not state that EPL is globally increasing in HMR. If the function $U$ has several local maxima, large changes in $\alpha$ may induce a jump in optimal job protection. Such a jump may either be upward or downward. When the jump is downward, optimal job protection goes down with the degree of HMR. We dispose of such a pathological case by the requirement that $t^{*}$ is unique.

Proposition 1 has three implications.

On the positive side, the model rationalizes the positive correlation between $\mathrm{HMR}_{t-1}$ and $\mathrm{EPL}_{t}$ reported in section 2. The model suggests that observed EPL heterogeneity in the cross-section of OECD countries may be partly explained by HMR heterogeneity across countries.

On the normative side, the model promotes a way to reform EPL. Policy makers should first reform the housing market. This would weaken the political support for employment protection, thereby making the labor market reform easier. Our estimates show that HMR affects EPL with a delay. Such a delay means that Governments must change the housing market regulation far in advance prior to changing the labor market legislation. This may not fit with the political agenda.

Finally, individuals are willing to lower their job opportunities in exchange for a lower housing price. Without HMR, EPL would simply maximize the employment probability $e(t)=m(t) p(t)$. Assuming an interior solution, optimal EPL would balance the marginal decrease in matching probability with the marginal increase in job-keeping probability. Formally, when $\alpha=0$, we have $e^{\prime}\left(t^{*}\right)=0$, which is equivalent to $t^{*} p^{\prime}\left(t^{*}\right) / p\left(t^{*}\right)=\left|t^{*} m^{\prime}\left(t^{*}\right) / m\left(t^{*}\right)\right|$. With HMR, the marginal impact of EPL on employment probability is negative, as agents account for the return on housing price. Indeed, the preferred EPL parameter results from $e^{\prime}\left(t^{*}\right) / e\left(t^{*}\right)=R^{\prime}\left(t^{*}\right) / R\left(t^{*}\right)<0$. This additional return on job security can explain why nonemployed young individuals may be in favor of a very strict EPL that reduces the odds of employment.

\section{Discussions}

We discuss several aspects of our model and some of its implications.

\subsection{Family support and social housing}

HMR causes a social demand for job protection. This is so because HMR creates risk aversion among individuals who are initially risk neutral. However, families and friends on the one hand, and the State on the other hand, typically provide housing for the deprived. In this subsection, we argue that such types of insurance raise the returns to EPL. 
Assume that nonemployed individuals benefit from some exogenous level of housing $h_{0}<\min _{t} w / R(t)$. This level may be provided by the family through living arrangements, or by some social housing policy. We refer to $h_{0}$ as nonmarket housing opportunities.

Ex-ante utility becomes

$$
U(t)=m(t) p(t) \frac{w}{R(t)}+[1-m(t) p(t)] h_{0}
$$

Assuming an interior solution, optimal EPL results from the following equality:

$$
\frac{p^{\prime}(t)}{p(t)}\left[1-\frac{h_{0}}{w / R(t)}\right]+\left|\frac{R^{\prime}(t)}{R(t)}\right|=\left|\frac{m^{\prime}(t)}{m(t)}\right|\left[1-\frac{h_{0}}{w / R(t)}\right]
$$

Proposition 2 Nonmarket housing opportunities and optimal job protection. Let $t^{*}$ be unique with $t^{*}>0$ and consider a marginal increase in nonmarket housing opportunities $h_{0}$. Then, optimal strictness of EPL $t^{*}$ goes up, that is $d t^{*} / d h_{0}>0$.

Parameter $h_{0}$ only affects the return to EPL in terms of employment probability, while leaving the return in terms of housing price unaffected. On the one hand, nonmarket housing opportunities make unemployment less painful, which reduces the employment return accordingly. On the other hand, this type of insurance does not target the particular housing market failure induced by HMR. The return on housing price stays unchanged as a result. It follows that the consideration of family support and social housing magnifies the distortion highlighted in this paper.

\subsection{Housing unemployment insurance}

Our model is based on the documented fact that unemployment episodes significantly increase the probability of mortgage default, or at least mortgage delinquency. Lenders confronted with HMR reward job security as a result. This phenomenon only arises because there is no housing unemployment insurance. If the unemployed could sign complete contracts with such an insurance company, the insurance would cover the worker's default, and lenders would be indifferent vis-à-vis job security. In turn, the social demand for job protection would decrease.

Housing unemployment insurance differs from regular unemployment insurance. Regular unemployment insurance partly covers the loss of income. It is induced by risk aversion, which our model abstracts from. In so far as insurance is incomplete, the default probability still exists. Indeed, workers can use unemployment benefits for various purposes, including mortgage payments, but also non-durable and other durable consumption. Complete insurance cannot be provided for obvious moral hazard reasons. In addition, young workers are generally unentitled to unemployment benefits because they have not paid taxes for sufficiently long. In other words, there is always room for housing unemployment insurance.

The market for private insurance on the rental market is virtually nonexistent. By contrast, mortgage unemployment insurance does exist. In case of full insurance, the price of the loan is equal to the marginal cost of money, i.e. $R=1$. Such a price no longer depends on job security. A balanced budget requires that the premium $\kappa$ paid by the worker be worth

$$
\kappa=(1-p) w
$$


This leads to the following maximum utility level

$$
U(t)=m(t) \frac{w-\kappa}{r}=m(t) p(t) \frac{w}{r}
$$

Workers' expected utility does not depend on HMR. Full insurance implies that HMR does not alter the demand for job protection.

However, there is evidence that mortgage unemployment insurance is incomplete. The literature mostly focuses on UK data (see for instance Pryce and Keoghan, 2001, 2002) and highlights the fact that high-risk workers are typically excluded from insurance coverage. ${ }^{7}$ Mortgage unemployment insurance contracts do not allow bank exposure to default risk to be reduced. This is probably so for various moral hazard problems that can be inferred from reading the insurance contracts: insurers want to avoid workers voluntarily choosing to default, either through voluntary unemployment or rational default when net equity becomes negative. In addition, unemployment risk, unlike other life risks, is heavily correlated across individuals, which creates aggregate risk for the insurer.

Incomplete insurance on the mortgage market and missing insurance on the rental market originate a demand for State-provided housing unemployment insurance. These policies reduce the political support for job protection. States already provide regular unemployment insurance, but do not separately insure borrowers against mortgage default. However, they may insure dwellers and pay the rent in case of default. This is especially true for youth who are excluded from unemployment insurance coverage.

\subsection{Short-term vs long-term jobs}

Between the end-1980s and the 2000s, European labor markets became more flexible via easier access to short-term contracts. In this subsection, we consider two types of contracts, namely regular contracts or long-term jobs and temporary contracts or short-term jobs. We argue that HMR can explain why people want to set taxes on the use of short-term contracts even though such taxes lower their employment probability.

For simplicity, we directly focus on a reduced-form model. The labor market part of the model extends the basic model to dual jobs, and reproduces the salient features of Blanchard and Landier (2002). There are two types of jobs, short-term and long-term, index by $S T$ and $L T$. Contracts differ in job security, with $p_{S T}$ the probability of keeping a short-term job and $p_{L T}$ the probability of keeping a long-term job, with $p_{L T}>p_{S T}{ }^{8}$ There is a tax $\tau$ on the use of short-term jobs. This tax has two effects. On the one hand, it reduces the matching probability $m=m(\tau)$. When $\tau$ increases, firms create fewer jobs and become more selective at the time of interview. On the other hand, it increases the proportion $q=q(\tau)$ of long-term jobs amongst total employment. Firms offer long-term jobs more frequently.

As banks can observe the employment contract, they offer two different mortgages. The loan price for workers in a contract of type $i=S T, L T$ is

$$
R_{i}=1+\alpha \frac{1-p_{i}}{p_{i}}
$$

\footnotetext{
${ }^{7}$ Typical mortgage unemployment insurance contracts are only proposed to experienced (not-too-old) employees under a regular contract, feature an explicit period over which the worker is not covered, and allow payments to be delayed in case of delinquency rather than the insurance company substitutes for defaulting individuals.

${ }^{8}$ For a micro foundation of this setting see Blanchard and Landier (2002).
} 
Individuals in a short-term job pay a higher price than individuals in a long-term job. In the particular case where there are no housing market imperfections, the loan price does not depend on job security and $R_{S T}=R_{L T}=1$.

The preferred tax $\tau^{*}$ is defined by

$$
\tau^{*} \in \arg \max _{\tau \geq 0} m(\tau)\left[q(\tau) p_{L T} \frac{w}{R_{L T}}+(1-q(\tau)) p_{S T} \frac{w}{R_{S T}}\right]
$$

There may be a corner solution where $\tau^{*}=0$. In that case, individuals do not want to regulate the use of short-term contracts. In an interior solution, the preferred tax results from the f.o.c.:

$$
\frac{m^{\prime}(\tau)}{m(\tau)}\left[1+\frac{1-q(\tau)}{q(\tau)} \frac{p_{S T}}{p_{L T}} \frac{R_{L T}}{R_{S T}}\right]=\frac{q^{\prime}(\tau)}{q(\tau)}\left[1-\frac{p_{S T}}{p_{L T}} \frac{R_{L T}}{R_{S T}}\right]
$$

The marginal cost of the tax consists of a lower matching probability weighted by the average matching gain. The marginal benefit consists of a larger probability of having a long-term job. This gain is all the higher in so far as job security differs between contracts.

Proposition 3 HMR AND Short-term contract taxation. Let $\tau^{*}$ be unique with $\tau^{*}>0$ and consider a marginal increase in the degree $\alpha$ of HMR. Then, (i) the preferred tax on short-term contracts goes up, that is $d \tau^{*} / d \alpha>0$, and (ii) the employment rate goes down, that is $d e^{*} / d \alpha<0$.

Without HMR, the only purpose of the $\operatorname{tax} \tau$ is to maximize the employment probability. Although one may doubt that a positive tax could be efficient in that case, Blanchard and Landier argue that the gain in mean job security due to the increase in the proportion of offered long-term jobs can offset the loss in matching probability. Although the reduced-form model we use here is compatible with the Blanchard and Landier thesis, consideration of HMR strengthens the view thereby young people do not want jobs that increase the overall labor market risk. Housing market imperfections reduce the marginal cost of the tax and raise its marginal benefit. On the one hand, an increase in $\alpha$ raises the mortgage price. The real wage goes down as a result, which lowers the cost of the tax in terms of employment probability. On the other hand, an increase in $\alpha$ magnifies the gap between $R_{S T}$ and $R_{L T}$. Regular jobs become more attractive as a result.

Consequently, the preferred tax can be higher than the one that maximizes employment. Furthermore, the tax increases with the degree of HMR. Therefore, our model can help to understand why people are willing to tax the use of temporary jobs beyond the level that maximizes the odds of employment. Several European Governments have facilitated the use of temporary contracts over the past two decades, resulting in millions of jobs for European workers. However, such Governments were not systematically reelected, suggesting that people were dissatisfied with the new jobs. ${ }^{9}$

\subsection{Down-payment restrictions}

The basic model focuses on housing market distortions that increase the cost of foreclosure. Such distortions raise the return to job security as workers benefit from better loans. However, this mechanism presumes that individuals get access to the credit market. In this subsection, we analyze the effects of legislation that limits access to housing credit. We name the bulk of such legislation min down-payment

\footnotetext{
${ }^{9}$ See Boeri (2008).
} 
policies as it mostly increases the ratio of minimum down payment to value. We argue that such policies tend to lower support for job protection.

To introduce a min down-payment policy, households must be endowed with wealth to invest. Hereafter, we consider a particular individual whose wealth is $I$. Let $\eta$ denote the minimum down-payment ratio. The mortgage $E$ cannot exceed the fraction $\eta$ of the total purchased value, that is $E /(E+I) \leq \eta$, which is equivalent to $E \leq \frac{1-\eta}{\eta} I$.

Wealth endowments, even without down-payment requirements, impact the household borrowing cost. For a given mortgage $E$, the bank takes less risk with a wealthy borrower as, in case of foreclosure, the value recovered by the bank is $\min \{(1-\alpha)(E+I), w)$. Therefore, the bank exposure to risk goes down to zero when the wealth of the agent covers the possible foreclosure losses, that is. when $I>E+\frac{w}{(1-\alpha)}$.

Let $E^{b}$ denote the maximum amount a bank is willing to lend to an individual with wealth $I$ and wage $w$. We have

$$
E^{b}=p w+(1-p) \min \left\{(1-\alpha)\left(E^{b}+I\right), w\right\}
$$

Therefore,

$$
E^{b}=E^{b}(t, I, \alpha)=\left\{\begin{array}{l}
\frac{1}{r} \frac{p w+(1-p)(1-\alpha) I}{p+\alpha(1-p)} \text { if } I \leq I^{b} \\
w \text { if } I>I^{b}
\end{array}\right.
$$

with $I^{b}=w \alpha /(1-\alpha)$ the threshold above which the bank considers the household to be a risk-free borrower.

Due to the min down-payment policy, the household may not be able to borrow the maximum amount that the bank is willing to lend. The maximum mortgage is now defined by $E=\min \left\{E^{b}, I(1-\eta) / \eta\right\}$.

The preferred EPL parameter results from

$$
t^{*}(I, \alpha, \eta) \in \arg \max _{t \geq 0} m(t) p(t) \min \left\{E^{b}(t, I, \alpha)+I, I / \eta\right\}
$$

We study the solution to the maximization problem in two steps. First, we focus on the unconstrained solution, that is the preferred EPL parameter if the min down-payment policy did not exist. Second, we focus on the constrained solution and conclude.

Let $t^{* *} \geq 0$ denote the employment-maximizer EPL parameter. In an interior solution, the preferred EPL parameter $t^{b}$ solves:

$$
\frac{t^{b} p^{\prime}\left(t^{b}\right)}{p\left(t^{b}\right)}\left[1+\varepsilon\left(t^{b}, I, \alpha\right)\right]=\left|\frac{t^{b} m^{\prime}\left(t^{b}\right)}{m\left(t^{b}\right)}\right|
$$

where $\varepsilon$ is the elasticity of maximum housing spending vis-à-vis the probability of mortgage reimbursement $p$. This elasticity is defined by

$$
\varepsilon(t, I, \alpha)=\left\{\begin{array}{l}
\frac{\alpha w-I(1-\alpha)}{(I+p w)(p+\alpha(1-p))} \text { if } I \leq I^{b} \\
0 \text { if } I>I^{b}
\end{array}\right.
$$

As $\varepsilon$ is decreasing in $I, t^{b}$ decreases with individual wealth, reaching $t^{* *}$ when $I=I^{b}$. HMR increases the demand for job protection among individuals whose wealth is lower than $I^{b}$ as $\varepsilon(t, I, \alpha)$ is increasing in $\alpha$ for those values of $I$.

Now, consider the constrained solution $t^{d}$. When banks are constrained, a decrease in $t$ does not affect the housing consumption of the consumer but does increase their likelihood of being employed as long as $t>t^{* *}$. The EPL parameter is set so as to make $E^{b}+I$ and $I / \eta$ equal. Two cases must be distinguished. 
When $\alpha \leq \eta$, the min down-payment policy is restrictive compared to the housing market imperfection. The maximum amount that banks are willing to lend is always larger than the maximum amount induced by the law. The optimal EPL parameter $t^{d}=t^{* *}$ in that case and individuals enjoy $I / \eta$ units of housing consumption. When $\alpha>\eta$, using (25), $t^{b}$ is unique and solves

$$
p\left(t^{d}\right)=\frac{(\alpha-\eta) I}{\eta w-(1-\alpha) I}
$$

The parameter $t^{d}$ is increasing in $I$ and goes from $\underline{t}^{d}<0$ when $I=0$ to infinity when $I=w \frac{\eta}{1-\eta}$. Note also that $t^{d}$ is increasing in both $\alpha$ and $\eta$ as long as $\alpha>\eta$ and $I<w \frac{\eta}{1-\eta}$.

The preferred EPL parameter follows. When $\alpha \leq \eta$, individuals borrow less than the banks would like to lend and $t^{*}(I, \alpha, \eta)=t^{* *}$. When $\alpha>\eta$, individuals may be constrained or not by the min down-payment policy. Then,

$$
t^{*}(I, \alpha, \eta)=\left\{\begin{array}{l}
t^{* *} \text { if } I \leq \underline{I} \text { or } I \geq I^{b} \\
t^{d}(I, \alpha, \eta) \text { if } I \in(\underline{I}, \bar{I}) \\
t^{b}(I, \alpha) \text { if } I \in\left[\bar{I}, I^{b}\right)
\end{array}\right.
$$

with $\bar{I}$ such that $t^{d}(\bar{I}, \alpha, \eta)=t^{b}(\bar{I}, \alpha, \eta)$.

Proposition 4 Wealth and optimal job protection (i) When the down-payment ratio is larger than the degree of HMR, $\alpha<\eta$, all individuals prefer the employment-maximizer EPL parameter $t^{* *}$. (ii) When the down-payment ratio is lower than the degree of HMR, $\alpha>\eta$, individuals endowed with low or high wealth prefer $t^{* *}$ while individuals in the middle of the wealth distribution prefer more protected jobs. Preferred EPL is first increasing and then decreasing in wealth endowment.

Individuals do not need excess job protection when $\alpha \leq \eta$, that is when the min down-payment policy is stricter than the degree of housing market imperfection. The case $\alpha>\eta$ is depicted by Figure 5 . The locus $t^{d}$ corresponds to constrained individuals whose best EPL parameter binds the min down-payment policy. The locus $t^{b}$ corresponds to unconstrained individuals who prefer an interior solution. Optimal EPL is first increasing, then decreasing in wealth. Neither poor nor rich individuals require extra job protection. The rich invest so much collateral that they are risk-free borrowers whatever the degree of job protection. The poor have too little collateral to invest and cannot expand their credit opportunities through additional job security. As wealth increases, individuals can relax the constraint imposed by the min down-payment policy and the preferred EPL parameter rises. Above $\bar{I}$, individuals are not constrained and the demand for EPL decreases with wealth. 


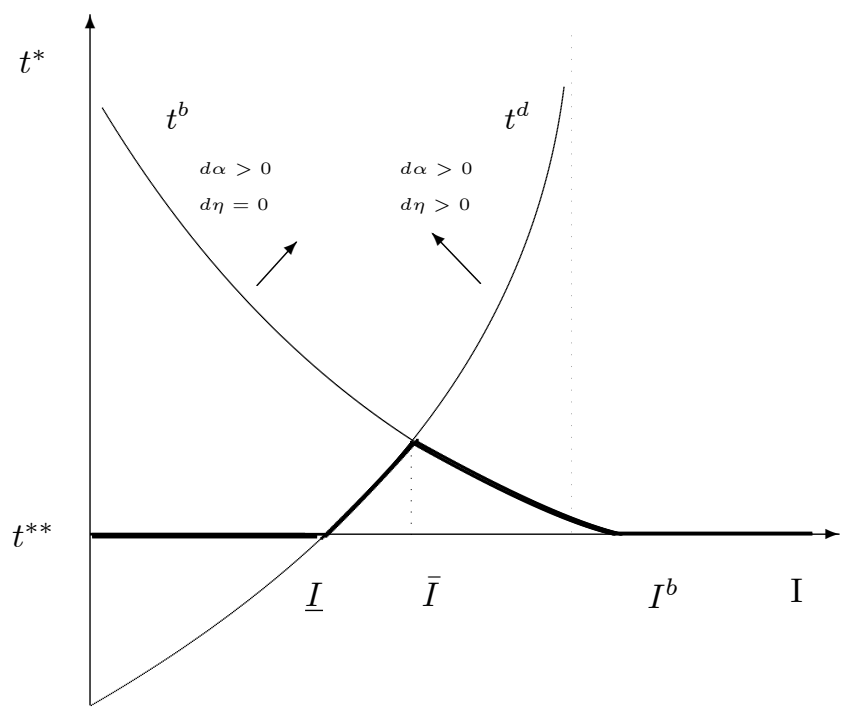

Figure 2: Optimal job protection as a function of individual wealth with min down-payment policy

Case $\alpha>\eta$. The preferred EPL parameter is depicted by the thick line

The effects of HMR and min-down payment policies can be described as follows.

Proposition 5 Down payment, HMR and job Protection (i) When $\alpha<\eta$, neither $\alpha$ nor $\eta$ have an impact on EPL. (ii) When $\alpha>\eta$, a marginal increase in $\eta$ reduces the set of constrained individuals and lowers the preferred EPL parameter among such individuals, while a marginal increase in $\alpha$ expands the set of individuals who need extra job protection, and increases the preferred EPL parameter among constrained and unconstrained individuals.

Proof. The results follow from comparative statics on $t^{d}$ and $t^{b}$.

Proposition 5 tells a general message: the demand for job protection increases with the degree of HMR in countries where mortgage credit is available. When the law restricts access to mortgage credit, there are no possibilities to expand credit opportunities with more secure jobs. Then, optimal EPL only corrects failures specific to the labor market, and deregulating the housing market has no impact on the social demand for job protection.

The scope for policy complementarity depends on the strictness of min down-payment policies. Figure 3 confronts the min down-payment ratio (latest data available) with the administrative cost of foreclosure (in percentage of the mortgaged house). The min down-payment ratio is on the x-axis, while the measure of housing market imperfection is on the y-axis. Figure 3 features two additional axes whose origin is defined by the median values of the depicted variables. The countries that are the most exposed to policy complementarity are located in the North-East part, while, conversely, the countries that are the least 
exposed to policy complementarity are located in the South-West part.

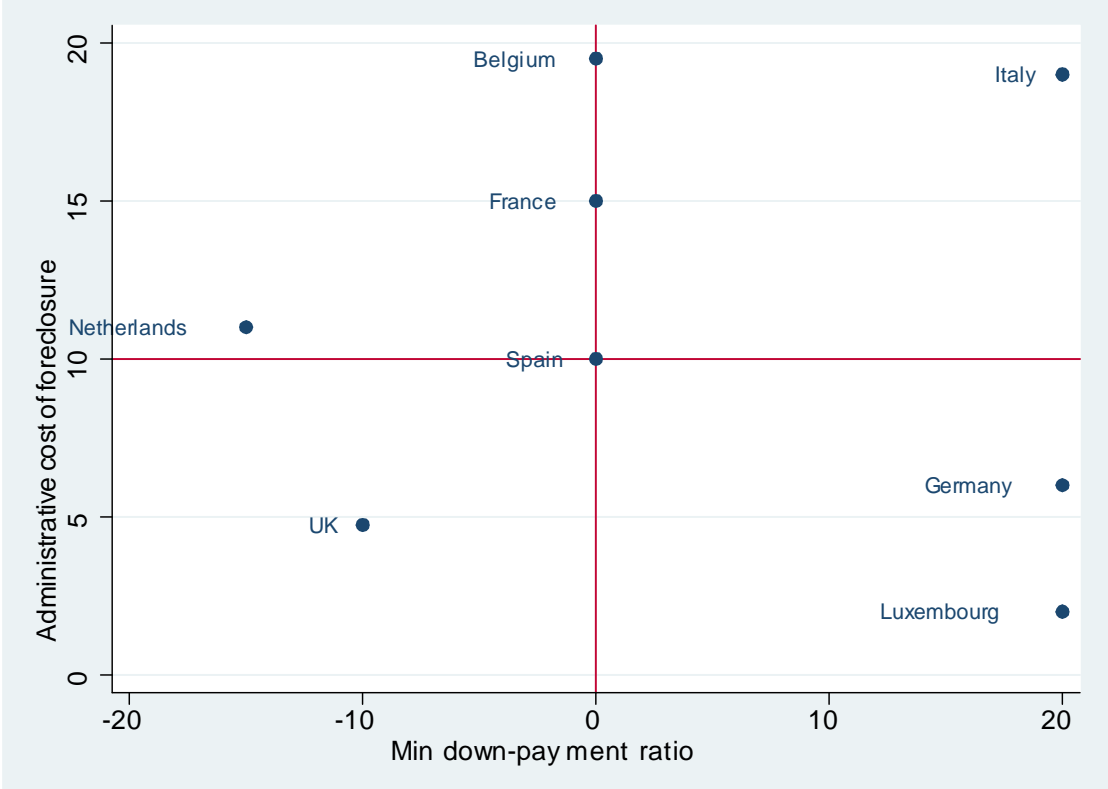

Figure 3: Administrative cost of foreclosure and min down-payment ratio. Source: legal expenses (in \% of property value) are from Chiuri and

Japelli (2003); the min down-payment ratio is from Lo Prete (2008)

Figure 3 displays two remarkable features.

First, the min down-payment ratio is low in our sample of countries. It never exceeds $20 \%$, and it is frequently negative, meaning that banks can lend more than the value of the house (either to finance regular consumption or to finance investments that may improve the value of the house). These weak values of the min down-payment ratio result from the financial market deregulation observed in the 1990s. In terms of Proposition 5, this means that $\eta$ is small, which opens the room for the relationship between EPL and HMR.

Second, the countries that are the most exposed to policy complementarity are Belgium, France, Spain, and more surprisingly the Netherlands. By contrast, first-time buyers do not easily have access to mortgage credit in Germany and Italy, while legal expenses of foreclosure seem too low in the UK.

\subsection{Feed-back effects from EPL to HMR}

The parameter $\alpha$ measures the distortions induced by HMR. Most of these distortions depend on the characteristics of the judicial system, as with its legal origins, the degree of law enforcement, or spendings in the correct functioning of the system. Some of the distortions are also induced by the legal protection that accrues to borrowers against lenders and to renters against landlords. We now focus on the demand for such a protection.

We make two changes. On the one hand, workers are partially insured against the default risk. The parameter $\varepsilon$ denotes the fraction of the good that the worker can enjoy when s/he defaults. This fraction obtains at some cost, as $\varepsilon$ increases distortions. Therefore, $\alpha=\alpha(\varepsilon)$, with $\alpha(0) \geq 0$, so that $\varepsilon$ is not the 
only source of distortion. In addition, there is no free lunch and $\alpha^{\prime}(\varepsilon) \geq 1$. What the worker gets is lost for the bank. Actually, the loss can be larger due to legal procedures and delays. Finally, we assume that the size of the distortions increases with the level of insurance coverage and $\alpha^{\prime \prime}(\varepsilon)>0$. As an example, we consider that $\alpha(\varepsilon)=\alpha_{0} \exp (\nu \varepsilon)$, with $\alpha_{0}<1$ and $\alpha_{0} \nu \geq 1$. The parameters $\alpha_{0}$ and $\nu$ are induced by the fundamental properties of the judicial system.

On the other hand, we account for additional default risks. With probability $1-\zeta$, the worker defaults when $\mathrm{s} /$ he has a job. The worker keeps the proportion $\varepsilon$ of the good when such a default occurs. $\mathrm{S} / \mathrm{he}$ obtains the proportion $\lambda \varepsilon$ when the default happens while the worker is unemployed. The parameter $\lambda$ accounts for the potential bias of judges when the person who makes default is unemployed. This bias can be positive $(\lambda>1)$, or negative $(\lambda<1)$.

The mortgage price $R$ must account for the two sources of mortgage default. We obtain $R=1+$ $\alpha(\varepsilon)(1-\zeta p) / \zeta p$. It is increasing in the distortion $\alpha$. Therefore, it increases with worker's degree of housing insurance $\varepsilon$. It is also decreasing in worker's probability $p$ of keeping the job, as it reduces the overall default probability.

The preferred degree of housing protection results from

$$
\max _{\varepsilon \geq 0} U=m[p(\zeta+\varepsilon(1-\zeta))+(1-p) \lambda \varepsilon] \frac{w}{R(\varepsilon)}
$$

The term $[p(\zeta+\varepsilon(1-\zeta))+(1-p) \lambda \varepsilon]$ is the ex-ante probability of housing enjoyment. It is increasing in the degree of housing insurance $\varepsilon$. However, $\varepsilon$ increases the mortgage price $R$, thereby reducing the amount of housing consumption.

The first derivative of $U$ with respect to $\varepsilon$ has the sign of

$$
g(\varepsilon)=\alpha \frac{\lambda(1-p)+p(1-\zeta)}{p \zeta}\left(1-\frac{\alpha^{\prime} \varepsilon}{\alpha}\right)-(1-\lambda) \frac{1-p}{1-p \zeta}-\left(\alpha^{\prime}-1\right)
$$

This sign can be positive or negative reflecting the antagonistic impacts of $\varepsilon$ on housing enjoyment probability and amount of housing consumption.

An increase in job security modifies the marginal return to $\varepsilon$ as follows:

$$
\operatorname{sign}\left(g_{p}\right)=\operatorname{sign}\left\{-\alpha \lambda\left(1-\frac{\alpha^{\prime} \varepsilon}{\alpha}\right)+(1-\lambda) \frac{1-\zeta}{\zeta}\left(\frac{p \zeta}{1-p \zeta}\right)^{2}\right\}
$$

The first term is due to the marginal impact of $p$ on the probability of housing enjoyment. The second term results from the fact that $p$ increases the expected amount of housing consumption, thereby raising the return to housing insurance. The global effect is ambiguous. Job security, therefore, has an ambiguous impact on the social demand for housing insurance.

To go a step further, we focus on the particular case where $\alpha(v)=\alpha_{0} \exp (\nu \varepsilon)$. Solving the first-order condition to the maximization problem gives:

$$
\alpha\left(\varepsilon^{*}\right)=\frac{p \zeta}{1-p \zeta} \frac{\lambda(1-p)+p(1-\zeta)}{\lambda(\nu-1)+p((\nu-1)(1-\lambda)+\zeta}
$$

The function $\alpha\left(\varepsilon^{*}\right)$ is first increasing and then decreasing in $p$. However, there is an interior solution when $\alpha\left(\varepsilon^{*}\right) \in\left[\alpha_{0}, 1\right]$. To illustrate the property of non-monotonicity, we consider a parameterization. The parameter $\zeta=.95$ and employed workers only have a small default probability. The parameter $\lambda=3$ and unemployed persons are better covered than employed individuals. The parameter $\alpha_{0}=.25$, which 
sizes distortions in the absence of housing insurance. The parameter $\nu=4$, which gives the elasticity of the distortion with respect to housing insurance.

Figure 4.5 plots $\varepsilon^{*}$ as a function of $p$.

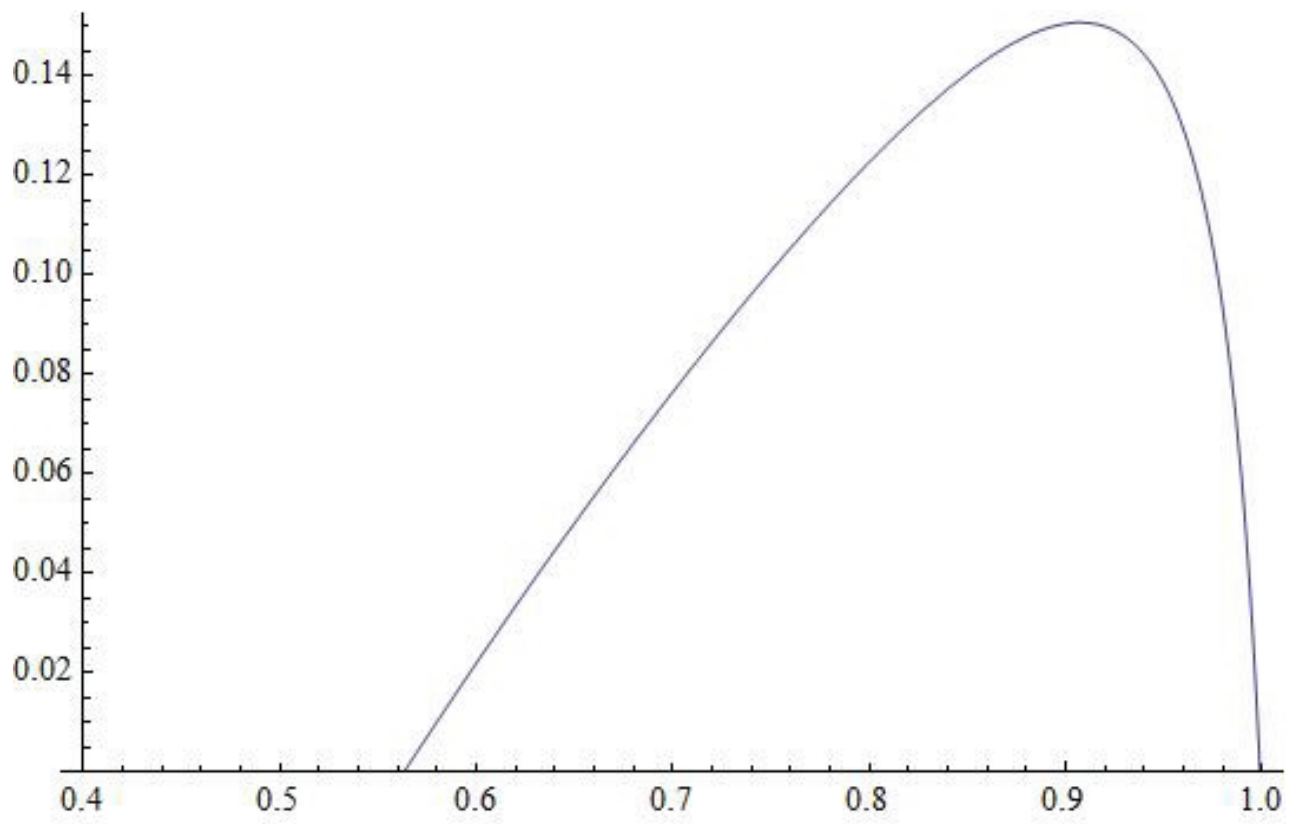

Optimal housing insurance $\varepsilon^{*}$ as a function of job security $p$. The set of parameters is $\lambda=3, \zeta=.95$,

$$
\nu=1 / \alpha_{0} \text {, and } \alpha_{0}=.25 \text {. }
$$

There is no demand for housing insurance when job security is low. The expected amount of housing consumption $w / R$ is so low that workers do not find it useful to increase the distortion $\alpha$ in order to be insured against the default risk. As $p$ becomes larger, the magnitude of optimal housing insurance increases. It is at most equal to $15 \%$ for a job loss probability around $8 \%$. The distortion $\alpha$ reaches .45, 20 percentage points higher than the level without housing insurance. Finally, optimal insurance decreases with job security, reflecting the fact that job security lowers the need for housing insurance.

\subsection{Back to the French CPE events: mismatch in policy reforms}

France is a good case study for our theory. International comparisons show that the housing market is highly regulated, the minimum down-payment ratio is low, regular jobs benefit from strict legislation, there are many short-term jobs, and youth are typically excluded from unemployment insurance. France experienced two policy reforms in 2006. On the labor market, a new contract was created. As explained in the introduction, the CPE mostly involved a regular job with an extended probation period. In terms of the models developed so far, the CPE can be analyzed as a reduction in job security, either through a decline in the EPL parameter $t$, or a fall in the short-term job tax $\tau$. On the rental market, the generosity of a public insurance against dweller's default was increased. This policy corresponds to a decline in parameter $\alpha$. Joint policy reform is exactly the type of policy we advertise in this paper. Unfortunately, the housing market reform took place months after the failure of the labor market reform, rather than before it or at the same time.

The rental market is highly regulated in France. Rents cannot easily change, typical contracts (baux) between the owner and the tenant last three years, and tenants cannot be evicted during the six-month 
winter season. Owners are encouraged to screen the applicants as a result, and there is evidence of low occupancy rates. To remedy the situation, the LocaPass program was created in 1998. This program is financed by employers' contributions on the total wage bill. The program has two main branches. The Avance Locapass pays the collateral asked by owners prior to renting. The money must be refunded within 36 months (the duration of the bail). The Garantie Locapass is a free insurance against renter's default. The State commits to pay at most 18 months over the 36 months of the bail of a rent contract. The tenant should repay the debt whenever possible. The insurance contract cannot be renewed. All employed tenants were initially covered. The insurance became available to students in 2001 .

The labor market reform took place in two steps. In August 2005, the Contrat Nouvelle Embauche was born. This contract was a regular contract with an extended probation period (from 6 months to two years), only available in small firms (less than 20 employees), and allowed employers to fire the workers under probation without formal motives. In January 2006, the Contrat Première Embauche followed. This contract was specific to those under 26 of age, and generalized the CNE to all firms. Youth started to demonstrate in March, and many faculties were closed during two weeks. The CPE was stopped in April 2006. After judicial battles concerning the duration of the probation period and the possibility for employers to fire without justification, the CNE officially disappeared in 2008.

The LocaPass program was reformed in December 2006, well after the CPE was abandoned. First, entitlement criteria to Garantie LocaPass became less strict, allowing all employed persons under 30, including students under temporary contracts, and unemployed under 30, to benefit from the coverage. Second, a new insurance contract was created, the Pass-GRL. This contract is sold by private insurers. Owners pay a monthly premium amounting to 1.5 to $2.5 \%$ of the rent. The premium can be partly deduced from income tax. In exchange, there is a no-limit guarantee against the tenant's default. The insurance also covers damages incurred by the dwelling.

The point here is that the housing market reform took place after the failure of the labor market reform. Such a mismatch in policy reform should be avoided in the future.

\section{Conclusion}

This paper is about one fact and a possible explanation. The fact is the correlation between the degree of Housing Market Regulation (HMR) and the strictness of Employment Protection Legislation (EPL). The explanation is that HMR weakens lenders' and owners' property rights, which in turn motivates the demand for job protection.

We show that the two sets of regulations are positively correlated in the cross-section of OECD countries. Using dynamic panel data for 15 countries over 1970-2000, we also show that the correlation holds within countries, and is robust to the consideration of an autoregressive component in the dynamic process of EPL. We then present a model in which the degree of HMR determines foreclosure costs on the housing market, while the strictness of EPL sizes administrative costs of dismissals. Banks respond to HMR by conditioning mortgage prices on job security. In that context, job protection is a second-best way to lower the mortgage price and facilitates access to housing. Finally, we consider various extensions that illustrate the usefulness of the basic model. Among them, we discuss the effects of other types of regulations that limit access to housing credit, and we explain why nonemployed individuals may favor a tax on short-term contracts despite the fact that it lowers their employment probability. 
Reforming the labor market is not an easy task. Most European countries have chosen to facilitate the use of temporary contracts rather than weakening the protection on regular contracts. These policies are not popular in countries where the housing market is highly regulated. The reform would be easier if the housing market were reformed first. Typical reforms would reestablish lenders' and owners' property rights. For instance, the State could provide compulsory mortgage and rental insurance. This type of insurance would come at a cost, but would also considerably lower the social demand for job security. In this perspective, the failure of the 2006 French reform of employment contracts is illuminating. A reform of the housing market took place months after the end of the law proposal.

Our paper could be extended in various directions. First, the model is very tractable, but it is too simple to analyze complicated reforms, dynamic effects, or to discuss the relationship between age and preferred job protection. Second, the model takes HMR as given. It would be interesting to go beyond our short discussion of the feed-back effects of HMR on EPL. Finally, we would like to test the microeconomic implications of the theory on individual data. 


\section{APPENDIX}

\section{A Endogenous wages}

In this Appendix, we examine the case of endogenous wages.

The contract space has the following restrictions. First, wages are set before the idiosyncratic shock, and they cannot be changed once the shock is known. Second, the contract cannot stipulate any payment from the firm to the worker in case of separation. This restriction implicitly results from out-of-model moral hazard problems. Third, the firm cannot credibly commit not to fire the worker in case of adverse productivity shock. The contract space is, therefore, incomplete, which may originate a demand for employment protection even though agents are risk neutral.

The wage may depend on EPL, i.e. $w=w(t)$. In such a case, the general reasoning remains unaffected provided that

$$
-\frac{F(w(t)-t)}{1-F(w(t)-t)}<w^{\prime}(t)<1, \text { for all } t
$$

These restrictions ensure that $m^{\prime}(t)<0$ and $p^{\prime}(t)>0$. The social demand for EPL results from

$$
\frac{m_{w}}{m} w^{\prime}+\frac{m_{t}}{m}+\frac{p^{\prime}}{p}-\frac{p^{\prime}}{p} w^{\prime}+\frac{w^{\prime}}{w}-\frac{R^{\prime}}{R}+\frac{R^{\prime}}{R} w^{\prime}=0
$$

where $m=m(w(t), t), w^{\prime}=w^{\prime}(t), p=p(t-w(t))=1-F(w(t)-t)$, and $R=R(t-w(t))$. Using the fact that

$$
\frac{m_{w}(w, t)}{m(w, t)}=\frac{1-F(w(t)-t)}{F(w(t)-t)} \frac{m_{t}(w, t)}{m(w, t)}
$$

and

$$
\frac{R^{\prime}(t-w(t))}{R(t-w(t))}=-\frac{\alpha}{\alpha+(1-\alpha) p(t-w(t))} \frac{p^{\prime}(t-w(t))}{p(t-w(t))}
$$

We finally obtain

$$
\frac{t p^{\prime}}{p}\left[1+\frac{\alpha}{\alpha+(1-\alpha) p(t-w(t))}\right]\left(1-w^{\prime}\right)+\frac{t w^{\prime}}{w}=\left|\frac{t m_{t}}{m}\right|\left(1+\frac{1-F}{F} w^{\prime}\right)
$$

However, there is another difficulty with endogenous wages: depending on the wage setting, the wage may depend on HMR index $\alpha$. Suppose that the wage results from Nash bargaining over expected match surplus, i.e.

$$
w(t) \in \arg \max _{w}\left\{Z(w, t)=\beta \ln \left(p(w, t) \frac{w}{R(w, t)}\right)+(1-\beta) \ln \pi(w, t)\right\}
$$

where $\beta \in(0,1)$ is worker's bargaining power. This case is slightly more difficult to analyze, because (i) the wage alters the mortgage price $R$, and (ii) the index of $\operatorname{HMR} \alpha$ also affects $R$, thereby changing the bargained wage.

Note that $Z(0, t)$ is minus infinity. In addition, there is a unique $w_{+}(t)$ such that $\pi(w, t) \geq 0$ iff $w \leq w_{+}(t)$. It follows that the first-order condition is necessary and the bargained wage $w(t) \in\left(0, w_{+}(t)\right)$ satisfies

$$
\beta \frac{\pi(w, t)}{1-F(w-t)}=(1-\beta) \frac{w}{1+\frac{w p_{w}(w, t)}{p(w, t)}-\frac{w R_{w}(w, t)}{R(w, t)}}
$$

Noting that

$$
\frac{w R_{w}(w, t)}{R(w, t)}=-\frac{\alpha}{\alpha+(1-\alpha) p(w, t)} \frac{w p_{w}(w, t)}{p(w, t)}
$$


we finally get

$$
w(t)=\frac{\beta A(w(t), t)}{1-\beta+\beta A(w(t), t)}\left[\mathbb{E}(y \mid y \geq w(t)-t)-\frac{F(w(t)-t)}{1-F(w(t)-t)} t\right]
$$

with

$$
A(w, t)=1+\frac{\alpha}{\alpha+(1-\alpha) p(w, t)} \frac{w p_{w}(w, t)}{p(w, t)}<1
$$

This wage rule features two important properties. First, the wage is a share of average output net of expected firing costs. Second, the bargained wage is decreasing in $\alpha$, the index of HMR, which raises the mortgage price. Indeed, increasing the wage deteriorates the probability of keeping one's job. This has a direct effect on worker's utility through the decline in probability of enjoying housing consumption. But, there is also an indirect effect whereby there is a further increase in the price that banks charge due to the rise in default probability.

The social demand for EPL still results from (38). The difference now is that changes in $\alpha$ have complicated effects on the marginal cost and benefit derived from EPL. However, all these new effects are second-order effects due to the positive impact of $\alpha$ on the loan price $R$ that deteriorates the wage $w$. They should be dominated by the first-order effect of $\alpha$ on the return to job security that is discussed throughout the paper.

\section{B Proof of Proposition 1}

(i) The profit function $\pi(w, t)$ is strictly decreasing in $t$, with $\pi(w, 0)>c$ and $\lim _{t \rightarrow \infty} \pi(w, t)=\int_{-\infty}^{\infty}(y-w) d F(y)=$ $\mathbb{E}(y)-w<c$. It follows that there is a unique $t_{+}$such that $\pi\left(w, t_{+}\right)=c$. The different assumptions on the matching technology implies that $\theta\left(t_{+}\right)=0$, so that $m(t)=0$ for all $t \geq t_{+}$. It follows that $U(t)>U\left(t_{+}\right)$for all $t<t_{+}$.

Now, let the function $\psi:\left[0, t_{+}\right] \times[0,1]$ be such that

$$
\psi(t, \alpha)=-\frac{\gamma(\theta(t))}{1-\gamma(\theta(t))} \frac{F(w-t)}{\pi(w-t)}+\frac{F^{\prime}(w-t)}{1-F(w-t)}\left[1+\frac{\alpha[1-F(w-t)]}{1-\alpha+\alpha[1-F(w-t)]}\right]
$$

By assumption, the f.o.c. to the maximization program $\left(\mathrm{P}_{1}\right)$ is necessary. We have

$$
U_{t}\left(t^{*}, \alpha\right)=U\left(t^{*}, \alpha\right) \psi\left(t^{*}, \alpha\right)=0
$$

which is equivalent to $\psi\left(t^{*}, \alpha\right)=0$. This gives equation (16).

We have $U_{t t}\left(t^{*}, \alpha\right)<0$ by definition of a maximum. But, $U_{t t}\left(t^{*}, \alpha\right)=U\left(t^{*}, \alpha\right) \psi_{t}\left(t^{*}, \alpha\right)$, which implies that $\psi_{t}\left(t^{*}, \alpha\right)<0$. Applying the implicit function theorem to the f.o.c. we obtain

$$
\frac{d t^{*}}{d \alpha}=-\frac{\psi_{\alpha}\left(t^{*}, \alpha\right)}{\psi_{t}\left(t^{*}, \alpha\right)}
$$

which has the sign of $\psi_{\alpha}\left(t^{*}, \alpha\right)$. But,

$$
\psi_{\alpha}(t, \alpha)=\frac{F^{\prime}(w-t)}{\{1-\alpha+\alpha[1-F(w-t)]\}^{2}}>0
$$

The result follows.

(ii) The employment probability induced by the preferred EPL parameter is $e\left(t^{*}\right)=m\left(t^{*}\right) p\left(t^{*}\right)$. The marginal impact of the degree of HMR $\alpha$ results from $e^{\prime}\left(t^{*}\right) d t^{*} / d \alpha$. We know from part (i) that $d t^{*} / d \alpha>0$. Therefore, the change in employment probability has the sign of $e^{\prime}\left(t^{*}\right)$. When $t^{*}>0$, we have $e^{\prime}\left(t^{*}\right) / e\left(t^{*}\right)=R^{\prime}\left(t^{*}\right) / R\left(t^{*}\right)<0$. 


\section{Other proofs}

The proofs of Propositions 2 and 3 are very similar to the proof of Proposition 1. The proofs of Propositions 4 to 6 are given in the body of the text. 


\section{References}

[1] Algan, Y., Cahuc, P., 2006. Job protection: the macho hypothesis. Oxford Review of Economic Policy 22, 390-410

[2] Algan, Y., Cahuc, P., 2009. Civic virtue and labor market institutions. American Economic Journal: Macroeconomics 1, 111-145

[3] Allard, G., 2005. Measuring job security over time: in search of a historical indicator for EPL (Employment Protection Legislation). Instituto de Empresa Working Paper 05-17

[4] Becker, S., Bentolila, S., Fernandes, A., Ichino, A., 2009. Youth emancipation and perceived job insecurity of parents and children. Journal of Population Economics, forthcoming

[5] Balas, A., La Porta, R., Lopez-de-Silanes, F., Shleifer, A., 2009. The divergence of legal procedures. American Economic Journal: Economic Policy 1, 138-162

[6] Blanchard,O., Landier, A., 2002. The perverse effects of partial labour market reform: fixed-term contracts in France. Economic Journal 112, F214-F244

[7] Blanchard, O., Tirole, J., 2008. The joint design of unemployment compensation and employment protection: a first pass. Journal of the European Economic Association 6, 45-77

[8] Blundell, R., Bond, S., 1998. Initial conditions and moment restrictions in dynamic panel data models. Journal of Econometrics 87, 115-43.

[9] Boeri, T., 2008. The paradox of disappearing European unemployment. Vox column, 23 April 2008, http://www.voxeu.org/index.php?q=node/1075

[10] Boeri, T., Conde Ruiz, J.I., Galasso, V., 2003. Protecting against labor market risk: firing costs or unemployment Insurance? CEPR Discussion Paper N. 3990

[11] Boeri, T., Garibaldi, P., 2009. Beyond Eurosclerosis. Economic Policy 24, 409-461

[12] Botero, J., Djankov, S., La Porta, R., Lopez-De-Silanes, F., 2004. The regulation of labor. Quarterly Journal of Economics 119, 1339-1382

[13] Cahuc, P., Carcillo, S., 2006. The shortcomings of a partial release of employment protection laws: the case of the 2005 French reform. Economic Policy Web Essays and Comments, November

[14] Chetty, R., 2008. Moral hazard vs. liquidity and optimal unemployment insurance. Journal of Political Economy 116, 173-234

[15] Chiuri, M.C., Jappelli, T., 2003. Financial market imperfections and home ownership: a comparative study. European Economic Review 47, 857-875

[16] Deng, Y., Quigley, J.M., Van Order, R., Mac, F., 1996. Mortgage default and low downpayment loans: the costs of public subsidy. Regional Science Urban Economics 26, 263-285

[17] Djankov, S., La Porta, R., Lopez-De-Silanes, F., Shleifer, A., 2003. Courts. Quarterly Journal of Economics 118, 453-517 
[18] Eichholtz, P.M.A., 1995. Regional economic stability and mortgage default risk in the Netherlands. Real Estate Economics 23, 421-439

[19] Kugler, A., Pica, G., 2006. Effects of employment protection and product market regulations on the Italian labor market. In J. Messina, C. Michelacci, J. Turunen, and G. Zoega, eds., Labour market adjustments in Europe, Edward Elgar

[20] La Porta, R., López-de-Silanes, F., Shleifer, A., Vishny, R., 1997. Legal determinants of external finance. Journal of Finance 52, 1131-1150

[21] Lo Prete, A., 2008. Internal risk sharing and international consumption responsiveness to income shocks: OECD evidence. EUI Working Papers MWP 2008/03

[22] Postlewaite, A., Samuelson, L., Silverman, D., 2008. Consumption commitments and employment contracts. Review of Economic Studies 75, 559-578

[23] Pryce, G., Keoghan, M., 2001. Determinants of mortgage protection insurance take-up. Housing Studies 16, 179-198

[24] Pryce, G., Keoghan, M., 2002. Unemployment insurance for mortgage borrowers: is it viable and does it cover those most in need? European Journal of Housing Policy 2, 87-114

[25] Roodman, D., 2006. How to Do xtabond2: An Introduction to "Difference" and "System" GMM in Stata. Center for Global Development Working Paper 103

[26] Saint-Paul G., 2001. Political economy of the labour market. Oxford and New York: Oxford University Press

[27] Saint-Paul, G., 2002. The political economy of employment protection. Journal of Political Economy $110,672-704$

[28] Serrano-Diaz, L., 2005a. On the negative relationship between labor income uncertainty and homeownership: risk aversion vs. credit constraints. Journal of Housing Economics 14, 109-126

[29] Serrano-Diaz, L., 2005b. Income volatility and residential mortgage delinquency across the EU. Journal of Housing Economics 14, 153-177 